Recebido: $15 / 05 / 2018$

Aprovado: 22/06/2018

\title{
Alexandre Magno: Um conquistador de seu próprio tempo
}

Danilo Bernardino*

Resumo: Tendo adotado uma relativa variedade de costumes persas, tais quais insígnias e trajes, e promovido ações como a integração de todo um contingente persa ao exército macedônico parte da literatura especializada - em função disso, o público em geral também - criou uma imagem idealizada do rei Alexandre. Sob essa perspectiva, personificada em figuras como a de Droysen (1833) e, em seguida, de Tarn (1933), Alexandre teria a clara e nobre intenção mediante a sua expedição ao Oeste asiático de unir greco-macedônios e persas em uma mesma e original sociedade a partir de uma perspectiva conciliadora, quase aos moldes democráticos modernos. Ao contrário, pretende-se apresentar uma alternativa que vai de encontro com essa já antiga tese, isto é, de que a fundação por Alexandre de uma nova monarquia pessoal apenas foi possível graças a uma antiga cultura política de criação de impérios universais oriunda desse mesmo Oeste asiático, fundada pelo grande Império neo assírio e perpetuado pelo império neo Babilônico e Aquemênida. Dessa maneira, coloca-se em perspectiva as conquistas macedônicas e o idealismo do rei macedônio, de modo a refutar uma inspiração individual de união dos povos oriunda da Grécia. Para abrir caminho para essa tese, se fará a análise de três momentos decisivos durante as expedição de Alexandre que foram comumente percebidos como tentativas de integrar os persas e os macedônios de forma igual, mas que, na realidade, apenas evidenciam que o novo modelo de dominação arquitetado pelo rei mantinha uma hierarquia rígida entre macedônios, dominadores, e persas, dominados.

Palavras-chave: Alexandre III; Reino da Macedônia; Império Aquemênida.

Abstract: By adopting a wide variety of Persian costumes, including insignias, clothes and many habits, for a long time historians and the public in general have created an idealized image of Alexander. In this perspective, the Macedonian king had a clear intention of uniting both Macedonian and Persian people in a single and original humankind brotherhood in an almost democratic ideal. In contrast, I intend to

\footnotetext{
Mestrando pelo programa de pós-graduação em História da Universidade de Brasília. danilobernardino20@gmail.com
} 
demonstrate, building on the ideas of Beaulieu, that the foundation of a personal monarchy by Alexander of Macedon has its origins in a political culture from the Near East inaugurated by the Neo Assyrian Empire (911 - 612 b.C.), which developed this new model of governance known as the Universal Empire, and was followed by the neo Babylonian empire, and then by the Achaemenid empire. Thus, the new personal monarchy established by Alexander must be seen only as a continuity of a long political tradition of Universal Empires that started centuries before with the Assyrians, and not as an attempt to build an original and democratic myth as was commonly argued and still perpetuated. In order to defend this thesis, I will investigate three key moments during the Asiatic expedition in which it is possible to identify evidences that the hierarchy between Macedonians and Persian were maintained in a conqueror/conquered logic.

Keywords: Alexander III; Macedonian Kingdom; Achaemenid Empire. 


\section{A natureza política do império fundado por Alexandre}

Alexandre III viveu no século quarto antes de Cristo (356 - 323), filho de um rei macedônio e de uma princesa do Épiro, no seio da tradicional dinastia Argeada. O reino da Macedônia herdado por ele de seu pai Filipe II até então não gozava de grande protagonismo no mundo grego, na realidade, ainda hoje, muito se discute acerca do seu real pertencimento ao mundo grego ${ }^{1}$. Sobre as origens desse reino, a tradição mais antiga que se tem notícia é encontrada em Heródoto, e está atrelada a um grego, chamado Perdicas, procedente de Argos e descendente da dinastia dos Temenos, que teria chegado com seus irmãos ao extremo norte da Grécia por volta do século VII e fundado a dinastia à qual pertenceu Alexandre (HDT. 8. 137-8). Apesar da distância - mesmo geográfica - do mundo grego, a grande capacidade de liderança e as reformas militares propostas por Filipe e levadas à cabo por Alexandre levaram os macedônios à consecutivas vitórias políticas e militares que reposicionaram o mapa político grego e, em seguida, do Oeste asiático, colocando na centralidade do mundo conhecido o setentrional e esquecido reino macedônico

Como uma das consequências das vitórias na Ásia, a vida de Alexandre foi visitada e revisitada incontáveis vezes desde a sua morte á propósitos específicos, de forma que o Alexandre Magno que paira hoje no imaginário coletivo parece ser apenas uma figura imbuída de valores e expectativas alheios ao seu próprio tempo. Todo esse conjunto de explicações para a vida de Alexandre e a grande distância temporal que nos separa do rei macedônio, no entanto, não significam que o estudo da vida desse individuo,

\footnotetext{
${ }^{1}$ Por um lado, temos os discursos do político ateniense Demostenes, para quem Filipe II, pai de Alexandre, era um bárbaro que ameaçava a liberdade grega. De fato, a entrada de Filipe na Afictionia de Delfos, assim como sua vitória contra uma coalizão liderada por atenienses e tebanos em Queroneia lhe conferiram uma posição hegemônica nos assuntos gregos. Essa condição gerou certo receio de alguns gregos como Demostenes na medida em que o reino macedônico se localizava nos limites setentrionais da Grécia, sendo distante das mais importantes cidades estado. Dessa forma, a Macedônia fazia fronteira com sociedades não gregas, como os trácios, e tal proximidade influenciava o modo de ser macedônico. Um desses traços que os afastavam mais ainda dos gregos era a forma de governo exercida na Macedônica, que ao contrário de Atenas, por exemplo, tinha o poder político e militar bastante concentrado nas mãos da monarquia. Para os gregos tal tipo de regime era considerado típico de povos não civilizados, portanto, não gregos. Por outro lado, há outro político ateniense que não via os macedônios como estrangeiros, pelo contrário, enxergava em Filipe a salvação dos gregos diante de possíveis investidas persas. De fato, não pode-se negar a forte influência da cultura grega na vida macedônica. Os macedônios falavam grego e cultuavam o panteão dos deuses gregos. Alexandre, por exemplo, optou, em sua chegada à Ásia Menor, por desembarcar na cidade de Troia, palco de um dos pilares da cultura helênica, e ofereceu sacrifícios ao herói grego, Aquiles. Os macedônios, ainda, participavam dos jogos olímpicos realizados em Olimpia, e se confraternizavam em banquetes (symposia), assim como os gregos.
}

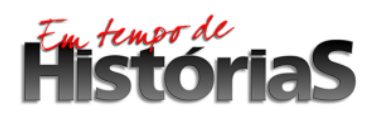


assim como de tudo que o cercava, seja metodologicamente impossível. Ao contrário, como defende Shipley (2007, p.318), o estudo do período Helenístico ainda engatinha, e há muito ainda a ser debatido e novamente explicado, uma vez que é nítido que têm-se observado nas últimas décadas que os estudos sobre o período têm ganhado um fôlego vigoroso, com a apresentação de novas respostas e, claro, de novas perguntas.

Com esse intuito, neste trabalho, pretende-se desmistificar a ideia já antiquada, mas ainda corrente, de um Alexandre mítico que idealizava, como disse Tarn, "transcender diferentes culturas nacionais" (WORTHINGTON, 2003, p. 206). Isso pois, entende-se que o rei Alexandre, como não poderia ser diferente, era e se comportava apenas como um homem de seu tempo, despreocupado com qualquer tipo de utopia de união dos povos, como muitas vezes pintado, dado a conquista rápida de um território tão heterogêneo. Ao contrário, Alexandre era consumido apenas pelo ardor da conquista e pela consolidação de uma nova monarquia pessoal que pretendia implantar, assim como defenderam Fredricksmeyer e Hammond ${ }^{2}$. Tal tentativa condiz com o que se poderia esperar de uma liderança política de seu espaço/tempo.

Deste modo, entende-se que o filho de Olímpia, longe de criar uma nova realidade racial e até mesmo democrática - como entendida em tempos modernos -, nos fornece indícios fortes encontrados nas fontes disponíveis de que, na realidade, seus principais objetivos iam ao encontro de uma já antiga tradição Mesopotâmica de estabelecimento de impérios universais ${ }^{3}$. Melhor dizendo, a criação de um novo nomos político no Oeste asiático por Alexandre apenas seguia uma trilha já percorrida, pela qual já haviam passado uma sucessão de impérios igualmente heterogêneos como o assírio, o babilônio e o persa, que, por sua vez, entrou diretamente em choque com Alexandre. Sabendo disso, defendese que somente essa longa tradição advinda do Oeste asiático - ou seja, de fora da Grécia - teria permitido que o macedônio Alexandre III ambicionasse o forjamento de um império tão grande e heterogêneo, e não uma inspiração individual e isolada de consolidação de união dos povos como se poderia pensar, caso apenas se voltasse os olhos

\footnotetext{
2 Perspectiva revisionista inaugurada por Hammond (1986) e Fredricksmeyer (1997) que entende que Alexandre ao conquistar o Império persa em nenhum momento pretendeu suceder Dario como novo imperador Aquemênida, tampouco continuar sendo um rei macedônio. Na realidade, Alexandre estaria conscientemente fundando um novo modelo de monarquia, que usaria de símbolos persas e macedônicos para a criação de uma unidade no novo império.

${ }^{3}$ Sistema de interação entre duas entidades, sendo uma a metrópole dominante, que exerce sobre a outra, propriedade subordinada, controle político interno e externo - a soberania completa. (Doyle, 1986, p.12).
} 
para o mundo grego e se ignorasse a outra parte em questão. Com isso posto, coloca-se em perspectiva as conquistas macedônicas, com o propósito de valorizar uma tradição mais antiga e não grega.

Para refutar esse imaginário de Alexandre como um idealizador, e abrir caminho para a tese defendida, analisa-se três momentos da trajetória do rei macedônio que tradicionalmente são interpretados como indícios de uma tentativa premeditada de fundir a cultura grego-macedônica com a cultura persa em uma perspectiva conciliadora. Primeiro, o recrutamento e recepção de jovens persas para compor o exército macedônico. Segundo, os casamentos promovidos por Alexandre entre nobres macedônios e mulheres persas ocorridos na cidade de Susa, em 324 a.C. E, terceiro, a adoção por Alexandre de certos hábitos e trajes persas, após o êxito na derradeira batalha de Gaugamela. Dessa maneira, deseja-se demonstrar que longe de promover uma fusão entre culturas, Alexandre se preocupou em manter de forma pragmática uma hegemonia macedônica no novo império universal que ele pretendia instaurar.

\section{Jovens Persas}

A grande empreitada de invadir o império persa e adentrar territórios pouco, ou nada conhecidos pelos gregos ${ }^{4}$ exigiu do pequeno reino macedônico grande esforço de guerra, tanto em termos econômicos, quanto em recursos humanos. Ainda que a investida contra o império persa significasse oficialmente uma ação conjunta entre os membros da Liga de Corinto, na infantaria, a contribuição da Liga teria sido de apenas 7.000 soldados, já na cavalaria, a liga teria cedido apenas 600 cavaleiros gregos (GREEN, 2013:158), mais especificamente, Atenas só teria oferecido 700 homens e 20 navios $^{5}$ (MossÉ, 2004:26). Isso nos assinala uma certa desmotivação grega em relação a invasão macedônica, apesar de todos as tentativas de Filipe e Alexandre de se aproximarem das poleis antes e durante a expedição (GREEN, 2014: 49). No entanto, a pouca presença de soldados da Liga também pode ter sido uma decisão que partiu da própria Macedônia, sendo um sinal da

\footnotetext{
${ }^{4}$ Aristóteles acreditava que no cume do Hindu Kush seria possível avistar o mar, hipótese que Alexandre pôde descartar. As regiões mais afastadas ao leste, como China e Malásia, eram desconhecidas pelos gregos. ${ }^{5}$ Importante notar que Atenas contava na época com a maior frota do Egeu.
} 
pouca confiança que Alexandre tinha em relação aos gregos - e com razão ${ }^{6}$ (CARTLEDGE, 2004:124).

Durante a campanha à Índia, Alexandre, por necessidade de contingente, já contava com o apoio de cavaleiros persas, recrutados na Sogdiana e na Bactriana, que atuavam como tropas auxiliares, portanto, não integradas ao exército (Mossé, 2004: 76; BRIANT, 2010: 92). Todavia, Quinto Curcio (8.5) relata que pouco antes da partida para Índia, 327 a.C., Alexandre já teria selecionado cerca de trinta mil jovens estrangeiros, que seriam treinados para combater à maneira macedônica, aprenderiam o grego e, em seguida, seriam integrados ao exército ${ }^{7}$. Após três anos de treinamento, os chamados epigonoi se juntaram ao exército macedônico em 324 a.C. em Susa, Diodoro relata a apresentação desses novos soldados:

\begin{abstract}
"Chegou a Susa um corpo com cerca de trinta mil soldados persas, todos muito jovens e selecionados de acordo com a sua força e tipo físico. Eles foram recrutados mediante as ordens do rei e tiveram supervisão de professores por todo o tempo necessário. Eles estavam esplendidamente equipados à maneira macedônica e acamparam nos limites da cidades, onde fizeram apresentações, demonstrando suas habilidades e disciplina com o uso das armas." (DIOD. 17.108.1)
\end{abstract}

Segundo Quinto Curcio, esses jovens teriam sido recrutados e treinados para uma dupla função: primeiro, funcionariam bem como reféns, de modo a controlar possíveis revoltas nas províncias recém conquistadas; segundo, claro, seriam úteis também como soldados, com o objetivo de aumentar o poderio militar macedônico, uma necessidade que, por sinal, já havia sido sentida. Já para Plutarco, o recrutamento desses jovens fazia parte de um gradual processo de aproximação, ordenado por Alexandre, entre macedônios e estrangeiros, que tinha como propósito consolidar o domínio macedônico no oriente e integrar os estrangeiros (Alexandre, 47).

A causa do recrutamento e treinamento desses jovens é vista sob diferentes perspectivas na historiografia. Mossé é enfática quando diz que o objetivo de tal ação não passava por uma integração entre macedônios e orientais em nome de uma causa

\footnotetext{
${ }^{6}$ Alexandre e os macedônios não eram vistos por todos os helenos como legítimos representantes da Grécia. O orador ateniense Demostenes, por exemplo, entendia a expansão macedônica como uma invasão bárbara ao território grego (DEM. Filipicas. 4.33 - 4).

${ }^{7}$ Briant (2010:93) e Green (2013:371), explicam que esses jovens foram selecionados cuidadosamente entre as melhores famílias sob os critérios rigorosos de força física e inteligência e, ainda, teriam sido ensinados a língua grega, durante o treinamento militar.
} 
universalista, mas, apenas, compensar a falta de soldados (Mossé, 2004:78). Green vai na mesma direção de Mossé ao relatar que os jovens estrangeiros foram treinados para fortalecer o exército macedônico, debilitado pela expedição. No entanto, Green vai além e menciona um segundo objetivo, a médio prazo, de substituir a velha guarda macedônica pelos, como o próprio Alexandre teria chamado, "Sucessores" (GREEN, 2013:371). Briant corrobora com essa ideia ao dizer que o treinamento de estrangeiros visava, em um futuro próximo, o estabelecimento de um exército composto tanto por macedônios, quanto por orientais, e com uma estrutura Aquemênida (BRIANT, 2010:92).

Com isto posto, a incorporação ao exército de um contingente estrangeiro não parece se justificar, em um primeiro momento, para além de reunir esforços suficientes para fortalecer o seu poderio de fogo e apaziguar os ânimos dos conquistados, uma vez que os contingentes macedônicos já se exauriam e que todo grande império necessita de o mínimo apoio para garantir a sua governabilidade. Como apontado por Quinto Cúrcio, uma das funções centrais desse recrutamento estava em justamente aumentar a força do exército já debilitado e usar como reféns aqueles jovens que a partir daquele momento começariam a fazer parte da causa macedônica. Além disso, um detalhe revelador ainda a ser observado é o fato de que não há relatos de recrutamento de jovens macedônios, ou outros gregos para aprender a língua persa, muito menos para aprender a maneira estrangeira de combater, com seria natural e esperado diante de uma possível tentativa conciliadora de união dos povos.

Notando essa ausência e conhecendo os relatos das fontes, pode-se inferir que o episódio de incorporação dos epigonoi se configura apenas como um esforço pragmático que não vai além de tentativa de manter um exército robusto e controlar possíveis tensões nas regiões conquistadas. Logo, neste momento, não há indícios que levem a um entendimento que houve uma tentativa de fusão a partir da incorporação de contingentes estrangeiros às fileiras macedônicas, mas apenas um esforço necessário para a continuação das conquistas e o seu estabelecimento.

\section{Bodas de Susa}

Segundo Lane Fox (2004, p. 856), as "Bodas de Susa" foram de longe a festividade mais marcante organizada pelo rei macedônio. Alexandre promoveu uma 
série de casamentos, aos moldes persas ${ }^{8}$, entre princesas orientais e nobres macedônios $\left(\right.$ Arriano, 7.4) ${ }^{9}$. Plutarco e Diodoro relatam que Alexandre ofereceu aos seus mais nobres amigos, as mais nobres persas em um festejo com cerca de nove mil convidados. Nesse sentido, para se ter a dimensão da grandiosidade dessa celebração, durante a festa, a todos foram oferecidos uma taça de ouro para libações (Alexandre, 70; Diodoro, 17.107).

Dado os relatos das fontes, pode-se aferir a importância atribuída a esses casamentos, visto a suntuosidade do evento e os indivíduos envolvidos, integrantes da mais alta nobreza, tanto macedônica, quanto iraniana. Dessa maneira, supõe-se que haveria sim um forte interesse de Alexandre em aproximar, definitivamente, a nobreza macedônica com a nobreza persa. Uma justificativa plausível para tal interesse é o fato de que Alexandre não poderia governar mais apenas para os macedônios, mais uma vez, havia o fator de busca de governabilidade. Ao encontro disso, em uma passagem de Plutarco, essa aproximação seria vista como necessária por Alexandre, na medida em que seria o melhor caminho para a harmonia e a consolidação do novo império (Alexandre, 47). Ainda sob essa perspectiva. Briant enxerga a política dos casamentos por uma dupla necessidade do rei, primeiro, continuar com o processo de aproximação das elites iranianas, empregado desde o início da campanha asiática. E em segundo, simultaneamente, buscar a aceitação dos macedônios em relação a esse processo de aproximação (BRIANT, 2010, p.103). Isso, portanto, não é o mesmo que dizer que Alexandre percebia, ou queria fazer parecer que essa elite persa fosse igual à elite macedônica, mas somente que havia a necessidade de criar uma coesão nos territórios conquistados, de modo a se criar um contexto político favorável para se exercer a soberania sobre aquele território.

Nesse sentido, os casamentos em Susa, que em um primeiro olhar podem parecer um exemplo claro de uma tentativa de unir democraticamente persas e macedônicos, na verdade, se revelam como uma ocasião em que fica clara a manutenção da hierarquia entre dominados e dominadores, mais uma vez. Isso porque, é primordial notar que os casamentos se dão em apenas uma via, homens macedônios se casam com mulheres

\footnotetext{
${ }^{8}$ Seguindo os costumes persas, os noivos sentavam em cadeiras, e, então, após um brinde, as noivas entravam, pegavam seus noivos pelas mãos e os beijavam (ARRIANO 7.4).

${ }^{9}$ Durante as "Bodas de Susa", Alexandre se casou com a filha mais velha de Dario e, também, com uma filha de Artaxerxes III (ARRIANO, 7.4). Alexandre já havia se casado, anos antes, com a filha de Oxyartes, Roxana, que lhe deu o seu único filho, assassinado ainda criança junto a mãe anos após a morte do pai.
} 
persas, e não o contrário, isto é, não há relatos de mulheres macedônicas, casando-se com homens estrangeiros, como enfatiza Wortington:

“(...) Caso a sua intenção fosse de fato unir esses dois povos de modo igual, teria sido relativamente fácil trazer mulheres nobres da Grécia e atrasar um pouco as cerimônias para que elas chegassem. Na verdade, não há nada sobre isso, apenas mulheres persas se casaram com homens Greco-macedônicos" (WORTHINGTON, 2005: 217). ${ }^{10}$

Logo, percebe-se nesse caso que houve sim um real cuidado de aproximação, necessário em função de uma tentativa de consolidação de uma nova monarquia, como pode ser constado, por exemplo, na leitura dos relatos de Plutarco. No entanto, fica claro, que isso não é o mesmo que dizer que houve um esforço de unir igualmente macedônios e persas, dado que a lógica de dominação permanece, isto é, de um lado os conquistadores e do outro os derrotados em uma posição de resignação.

\section{Adoção de trajes e costumes persas}

A adoção de vestimentas persas se comportou como uma estratégia fundamental para legitimar o poder de Alexandre diante de seus novos súditos. Após a batalha de Gaugamela, o rei macedônio adotou diversos adereços persas que teriam essa função, entre eles estão: o diadema ${ }^{11}$, que acabou por se tornar o símbolo maior de sua monarquia, sendo, em seguida, também o maior símbolo das monarquias helenísticos; o zone, cinto persa, considerado entre os persas um símbolo de lealdade entre autoridades e subordinados; o chiton, túnica persa de cor púrpura com uma listra branca, que era um dos principais adereços dos reis persas (assim como a tiara ${ }^{12}$ ) (Collins, 2012:371).

\footnotetext{
${ }^{10}$ Tradução livre do texto em inglês: "If his aim was really top lace the two imperial races on equal footing, it would have been relatively easy for him to import the necessary brides from mainland Greece and delay the ceremony until they arrived. In fact there is nothing attested except Persian woman married to GrecoMacedonian men".

${ }^{11}$ A adoção do diadema por Alexandre da monarquia persa é alvo de debate historiográfico. Isso pois, muito se coloca em dúvida se o diadema, de fato, fazia parte da indumentária da nobreza persa, dado que não é encontrado na iconografia Aquemênida. Por outro lado, nos relatos de Xenofonte, em Cyropaedia (8.3.13), Ciro é descrito usando um diadema. Além da origem persa, também se especula que o diadema poderia ser oriundo das fitas de vitória distribuídas em jogos na Grécia, ou do próprio deus Dioniso, que usou, na mitologia grega, um adereço semelhante em sua visita à Índia.

12 A tiara era o maior símbolo da monarquia persa, sendo usada somente pelo Grande Rei. Alexandre não teria adotado a tiara, justamente para não se identificar de forma tão forte com os reis aquemênidas. Afinal, não seria seu desejo suceder os Grandes Reis (COLLINS, 2012, p.385).
} 
Em defesa de que a adoção desses trajes não significa uma tentativa de fundir igualitariamente a cultura persa junto a cultura macedônica, tem-se no relato de Plutarco (Alexandre, 45) que o início do uso de trajes mistos por Alexandre se deu apenas a partir de 330, ou seja, após a derradeira batalha em Gaugamela e a morte de Dario III. Isto é bastante relevante, pois, segundo Bosworth (p. 212), a adoção de trajes e costumes persas somente teria se dado pela concorrência de um novo pretendente ao império Aquemênida, Besso, que, por sua vez, após a morte de Dario III adotou o maior símbolo da monarquia persa, a tiara, como sinal de que tinha a pretensão de suceder o antigo rei persa como no Grande Rei (ARRIANO, 2. 25). Nessa lógica, a adoção naquele momento de parte da indumentária persa se explicaria por uma necessidade prática e urgente de Alexandre em legitimar sua posição de liderança - e não de sucessor persa, visto que Alexandre nunca adotou a tiara persa (PlutARCO. Alex. 45.2) - diante dos novos súditos o quanto antes, e não de promover uma fusão cultural de longa duração.

Outro indicio da não intenção de assimilar a cultura estrangeira mediante o uso de trajes persas foi a apropriação e distribuição por Alexandre de mantos persas de cor purpura apenas para macedônios (DIODORO, 17.77.5-6). Na corte persa, esses mantos eram distribuídos entre os mais próximos cortesãos do Grande Rei, os chamados purpurati. Alexandre manteve o mesmo costume, dado que era fundamental se aproximar do imaginário de liderança conhecido por seus novos súditos, no entanto, mais uma vez, o rei macedônio não misturou entre as posições de mais prestigio e de maior proximidade com ele macedônios e persas, colocando sempre seus compatriotas em uma relação de superioridade aos estrangeiros (WORTHINGTON, 2003:212), como já observado durante os casamentos em Susa. Tudo isso vai ao encontro da visão de Arriano sobre a lógica de adoção de trajes estrangeiros, quando este relata que essas adoções corresponderiam a uma tentativa direcionada, principalmente, aos persas, ou seja, uma ação com o fito de não parecer demasiadamente estranho aos seus olhos. Ao passo em que também funcionaria como um modo de demonstrar aos macedônios que ele, Alexandre, não dependeria apenas deles, uma vez que tinha um corpo de aliados muito maior (ARR. 7.29.4). Isto é, as razões apresentadas pelas fontes aparecem frequentemente com um caráter de ordem prática.

Além da adoção de certos itens do vestuário persa, em seguida, Alexandre em um costumeiro banquete decidiu implantar entre os membros de sua corte macedônica a proskynesis, ou prostração, um antigo hábito persa. Nesse momento, Calistenes, 
responsável pelo relato da expedição, recusou-se a se ajoelhar diante do rei. Isso porque, para os gregos, o ato da genuflexão era um gesto apenas oferecido à figuras divinas (GREEN, 2013:373). Já entre os persas, de acordo com Heródoto, era simples identificar se dois persas pertenciam a mesma classe. Caso pertencessem a uma mesma classe, se davam um beijo nos lábios, caso pertencessem a esferas um pouco distintas, se davam um beijo no rosto, mas se estivessem em classes muitos distantes, o mais humilde deveria prestar obediência, prostrando-se diante do outro sujeito pertencente a uma hierarquia superior (HDT.1.134). Portanto, na cultura persa o ato da curvar-se se configurava como um gesto comum, prestado em respeito a um indivíduo de classe superior, inclusive, diante do Grande Rei que não costumava atender aqueles que não se prostrassem diante dele (THEM.27.4-5). Como consequência de recusa de Calístenes, o nome do sobrinho de Aristóteles apareceu na lista dos traidores na chamada "conspiração dos pajens"13, e Calistenes foi executado como conspirador. A participação do sobrinho de Aristóteles, no entanto, na conspiração nunca foi, de fato, comprovada, sendo vista nas fontes como tendo uma clara ligação com a sua recusa de curvar-se diante de Alexandre

Apesar de parecer, mais uma vez, um esforço claro de fundir a cultura Aquemênida com a cultura grega, a tentativa de implantação de proskynesis não deve ser vista a partir desta perspectiva. Isso pois, incluir entre os gestos da sua nova corte a genuflexão, da mesma forma que a adoção de alguns itens da indumentária persa, indica apenas uma ação de aproximação da cultura que se tenta assimilar, com propósitos de estabelecer dominação. A genuflexão, nesses termos, seria de grande utilidade para Alexandre na criação de sua nova monarquia, uma vez que introjetaria nos olhos daqueles que não viam em Alexandre um líder, mas apenas um estrangeiro qualquer, a figura que se assemelharia àquilo que eles estavam acostumados a identificar como soberano. Nesse sentido, Wortington aponta que tal ação significaria apenas a formalização de um protocolo comum, necessário para a criação de uma coesão do novo império:

"A sua atitude de adotar o costume asiático da proskynesis (uma prática antiga que se resumia ao ate de prostrar-se diante do rei em sinal de obediência) pode ser vista como uma tentativa de unir seus homens e os estrangeiros em um protocolo único." (WORTHINGTON, 2005:198)

\footnotetext{
${ }^{13}$ Pajens eram os filhos da nobreza macedônica que cresciam na corte junto ao rei macedônio. A conspiração pretendia matar o rei Alexandre, mas sem êxito teve seus articuladores executados. A participação de Calistenes na conspiração jamais foi comprovada.
} 
Dessa maneira, é possível entender a tentativa da adoção da genuflexão somente como uma ação com um fim prático e não ideológico, ou seja, com o objetivo de estabelecer uma maior proximidade e incluir os seus novos súditos. Afinal, os persas estavam acostumados com esse tipo de prática e se prostraram diante de Alexandre desde o início, logo dar prosseguimento a esse antigo costume, claro, se configuraria como um gesto de empatia, necessária para a edificação de um novo império heterogêneo e promover a sua figura como novo líder. No entanto, com a má recepção dos macedônicos, a tentativa foi logo abandonada (PLUT. Alex.54.2) ${ }^{14}$.

\section{Conclusão}

Portanto, pode-se concluir que em momentos importantes em que atribuiu-se a Alexandre uma nítida intenção de criar uma nova cultura hibrida, na qual elementos gregos e persas coexistiriam de forma equilibrada, na realidade, nota-se que Alexandre apenas esteve preocupado em se legitimar como novo soberano e garantir a sua governabilidade. Isto é, longe de promover uma união pacifica de culturas, o rei preocupou-se em se aproximar de seus novos súditos para se estabelecer de forma prática como o seu novo líder. Essa aproximação, nesses termos, não deve ser confundida com desejos utópicos, mas como uma ação unilateral e pragmática para quem pretendia comandar um império multicultural. Nesse sentido, os casamentos consumados em Susa e o ensino de grego e treinamento militar aos moldes macedônicos para jovens estrangeiros absorvidos ao exército são exemplos contundentes de que a hierarquia entre macedônios e persas imposta por Alexandre existia e seria mantida. Melhor dizendo, macedônios e persas não eram iguais, a lógica de dominação já havia muito presente do Oeste asiático com antigos grandes impérios estava mantida.

\section{Referências Bibliográficas}

\section{Fontes}

14 “Ao recusar ferozmente a prosternação, Calistenes[...], dissuadindo Alexandre de adotar esta prática,

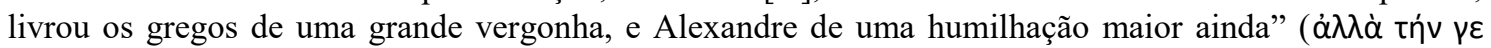

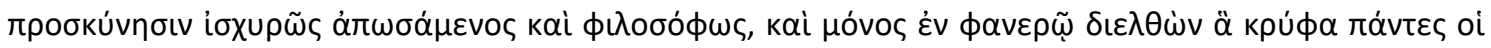

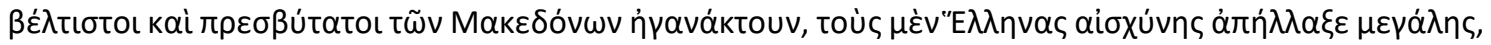

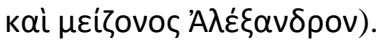


ARRIANO. Anabasis of Alexander. Tradução de P. A. Brunt. Cambridge, MA. London. Harvard University Press. 1983.

DIODORO DA SICÍLIA. Diodorus Siculus. Library of History. Tradução de C. Bradford. Cambridge, MA. London. Harvard University Press. 1963.

HERÓDOTO DE HALICARNASSO. Tradução de A. D. Godley. Cambridge, MA. London. Harvard University Press. 1938.

ISÓCRATES. Discursos. Tradução de Juan Manuel Guzmán Hermida. Madrid. Editorial Gredos. 1979.

JUSTINO. Justin. Epitome of the Philippic history of Pompeius Trogus. Tradução de J.C. Yardley. American Philological Association. 1994.

PLUTARCO. Plutarch's Lives: Demosthenes and Cicero. Alexander and Ceaser. Tradução de Bernardotte Perrin. Cambridge. MA. London. Harvard University Press. 1967.

. Plutarch's Lives: Aratus, Artaxerxes, Galba and Otho. Tradução de Bernardotte Perrin. Cambridge. MA. London. Harvard University Press. 1954.

QUINTO CÚRCIO, Curtius Rufus. History of Alexander. Tradução de John C. Rolfe. Cambridge. MA. London. Harvard University Press. 1946.

XENOFONTE. Cyropaedia. Tradução de Walter Miller. Cambridge, MA. London. Harvard University Press. 1960.

\section{Bibliografia}

BEAULIEU, Paul-Alain. World Hegemony, 900-300 BCE. In: SNELL, Daniel C. (org), A Companion to the Ancient Near East. Blackwell Publishing. 2005.

BRIANT, Pierre. Alexandre, o Grande. Porto Alegre. RS. L\&PM. 2010. Alessandro Magno: Dalla Grecia All'Oriente. Trieste, Editoriale Libraria. Electa/Gillimard.1992. From Cyrus to Alexander: a history of the Persian Empire. Indiana. Einsenbrauns. 2002.

BOSWORTH, A.B.. Alexander and the East: The Tragedy of Triumph. Oxford University Press. 1996.

CHAVALAS, Mark. The Age of Empires, 3100-900 BCE. In: SNELL, Daniel C. (org), A Companion to the Ancient Near East. Blackwell Publishing. 2005.

COLLINS, Andrew W. The Royal Costume and Insignia of Alexander the Great. American Journal of Philology, Vol. 133, N. 3, pp. 371-402. The Johns Hopkins University Press. 2012.

DOYLE, Michael W. Empire. Cornell University. Cornell University Press. 1986.

DROYSEN, Johann Gustav. Alexandre, o Grande. Rio de Janeiro. Contraponto Editora.

2010.

FREDRICKSMEYER, Ernst. Alexander the Great and the Kingship of Asia. In: BOSWORTH, A. B., BAYNHAM, E. J. (org), Alexander the Great in Fact and Fiction. Oxford. Oxford University Press. pp. 136-166. 2000.

FLOWER, Michael. Alexander the Great and panhellenism. In: Bosworth, Adrian; Baynham, Eric (orgs.). Alexander the Great in Fact and Fiction. Oxford. Oxford University Press. p. 96-135. 2000.

GREEN, Peter. Alexander of Macedon, 356-323 B.C.: A historical Biography. California. University of California Press. 1974.

GREEN, Peter. Alexandre, o Grande, e o Período Helenístico. Rio de Janeiro. Objetiva. 2014.

HAMMOND, Nicholas. The Kingdom of Asia and the Persian Throne. University of Adelaide/Cambridge. 1986.

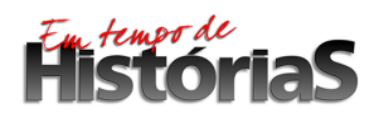


MOSSÉ, Claude. Alexandre, o Grande. São Paulo. Estação Liberdade. 2004.

SHIPLEY, Graham. Recent trends and new directions. In: Bugh, Glenn (Org). The Cambridge Companion to the Hellenistic world. Cambridge University Press. p. 315-326. 2007.

WORTHINGTON, Ian (org). Alexander and the "Unity of Mankind". Alexander the Great: a reader. London and New York: Routledge. p. 198-235. 2005. 